\title{
Catastrophic neurological complications of emergent endotracheal intubation: report of 2 cases
}

\author{
Mark E. Oppenlander, MD, ${ }^{1}$ Forrest D. Hsu, MD, ${ }^{1}$ Patrick Bolton, MD, ${ }^{2}$ and Nicholas Theodore, MD1 \\ 1Division of Neurological Surgery and ${ }^{2}$ Valley Anesthesiology Consultants, Department of Neurosurgical Anesthesia, Barrow \\ Neurological Institute, St. Joseph's Hospital and Medical Center, Phoenix, Arizona

\begin{abstract}
Although exceedingly rare, catastrophic neurological decline may result from endotracheal intubation of patients with preexisting cervical spine disease. The authors report on 2 cases of quadriplegia resulting from emergent endotracheal intubation in the intensive care unit.
\end{abstract}

A 68-year-old man with ankylosing spondylitis became quadriplegic after emergent intubation. A new $\mathrm{C6}-7$ fracturedislocation was identified, and the patient underwent emergent open reduction and C4-T2 posterior fixation and fusion. The patient remained quadriplegic and ultimately died of pneumonia 1 year later. This is the first report with radiographic documentation of a cervical fracture-dislocation resulting from intubation in a patient with ankylosing spondylitis.

A 73-year-old man underwent posterior C6-T1 decompression and fixation for a C6-7 fracture. On postoperative Day 12 , emergent intubation for respiratory distress resulted in C6-level quadriplegia. Imaging revealed acute spondyloptosis at C6-7, and the patient underwent emergent open reduction with revision and extension of posterior fusion from C-3 to T-2. He remained quadriplegic and ventilator dependent. Five days after the second operation, care was withdrawn. This is the first report of intubation as a cause of significant neurological decline related to disruption of a recently fixated cervical fracture.

Risk factors are identified and pertinent literature is reviewed for cases of catastrophic neurological complications after emergent endotracheal intubation. Strategies for obtaining airway control in patients with cervical spine pathology are also identified. Awareness of the potential dangers of airway management in patients with cervical spine pathology is critical for all involved subspecialty team members.

http://thejns.org/doi/abs/10.3171/2014.10.SPINE14652

KEY WORDS cervical spine; endotracheal intubation; quadriplegia

A LL classic maneuvers to establish an airway, including chin lift, jaw thrust, and direct laryngoscopy, can create significant movement within the cervical spine, ${ }^{3,18,20}$ thus rendering preexisting pathology in this region an important consideration for proper airway management. Neurosurgical patients are often classified as having a challenging airway when there is a history of cervical trauma or a state of physiological or iatrogenic limited cervical motion. ${ }^{7,8,14,16,22,24}$ Surprisingly, no consensus supports a particular practice option for airway management in these patients. $3,16,22$

In the setting of preexisting cervical spine pathology, complications of emergent endotracheal intubation resulting in spinal cord injury are exceedingly rare., ${ }^{9,16,19,22} \mathrm{We}$ describe 2 patients from the neurosurgery service with known cervical pathology. Each required emergent intubation in the intensive care unit that resulted in quadriplegia. In a unique manner, each case adds to the sparse literature on this devastating complication. We identify risk factors for each patient and discuss strategies for obtaining airway control in patients with cervical spine pathology. In an era of teamwork within medicine, we emphasize awareness by all subspecialty team members of the potential for complications in similar patients. 


\section{Case Reports}

\section{Case 1}

\section{History and Examination}

A 68-year-old man with a known history of ankylosing spondylitis sustained a ground-level fall on ice and experienced severe back pain. On admission, he had full strength without neurological deficit. Imaging revealed a T9-10 fracture-dislocation with shearing through the disc space and the posterior elements. No cervical fractures, subluxation, or other acute findings were identified on his initial cervical CT, which was confirmed by the neurosurgery service and an attending neuroradiologist upon independent review. Given the unstable thoracic fracture, the patient underwent an uncomplicated posterior decompression and fusion, including T9-10 laminectomy and T8-11 pedicle screw fixation. There was no difficulty with the patient's first intubation in the operating room.

Postoperatively, the patient was extubated and was able to move all extremities in the recovery room. On postoperative Day 1, however, he had decreased mental status associated with hypoxemia. After the failure of noninvasive measures such as the application of an oxygen mask, the trauma anesthesia team was called and intubation was attempted. Direct laryngoscopy revealed only the epiglottis. No vocal cords were visualized directly. The anesthesiologist was unable to pass a 7.5-mm cuffed endotracheal tube blindly. Fiberoptic laryngotracheoscopy was then performed and revealed significant vocal cord swelling. A 7.5$\mathrm{mm}$ cuffed endotracheal tube was again inserted into the trachea but could not be advanced beyond the vocal cords. Inserting a 7.0-mm cuffed endotracheal tube was then attempted, and the tube passed through the vocal cords.

The patient awoke with C-6 quadriplegia. Imaging revealed a C6-7 fracture-dislocation associated with severe central canal stenosis (Fig. 1A and B).

\section{Operation}

The patient was taken emergently to the operating room for open reduction and $\mathrm{C} 4-\mathrm{T} 2$ posterior segmental fixation (Fig. 1C and D).

\section{Postoperative Course}

The patient's mean arterial blood pressure was maintained above $85 \mathrm{~mm} \mathrm{Hg}$ for 7 days. However, he did not regain motor function. He required tracheostomy and placement of a percutaneous endoscopic gastrostomy tube before his transfer to a subacute care facility.

The patient returned to clinic 7 months postoperatively without improvement in the C-6 quadriplegia. Imaging showed excellent alignment with solid arthrodesis across both fracture sites. Unfortunately, the patient died of pneumonia 1 year after his injury.

\section{Case 2}

\section{History and Examination}

A 73-year-old man fell down a flight of stairs while on a cruise ship in the Baltic Sea. One week after the injury, he was transferred to Barrow Neurological Institute. On admission he displayed central cord syndrome, with muscle strength grade $3 / 5$ in his bilateral hand grips and triceps
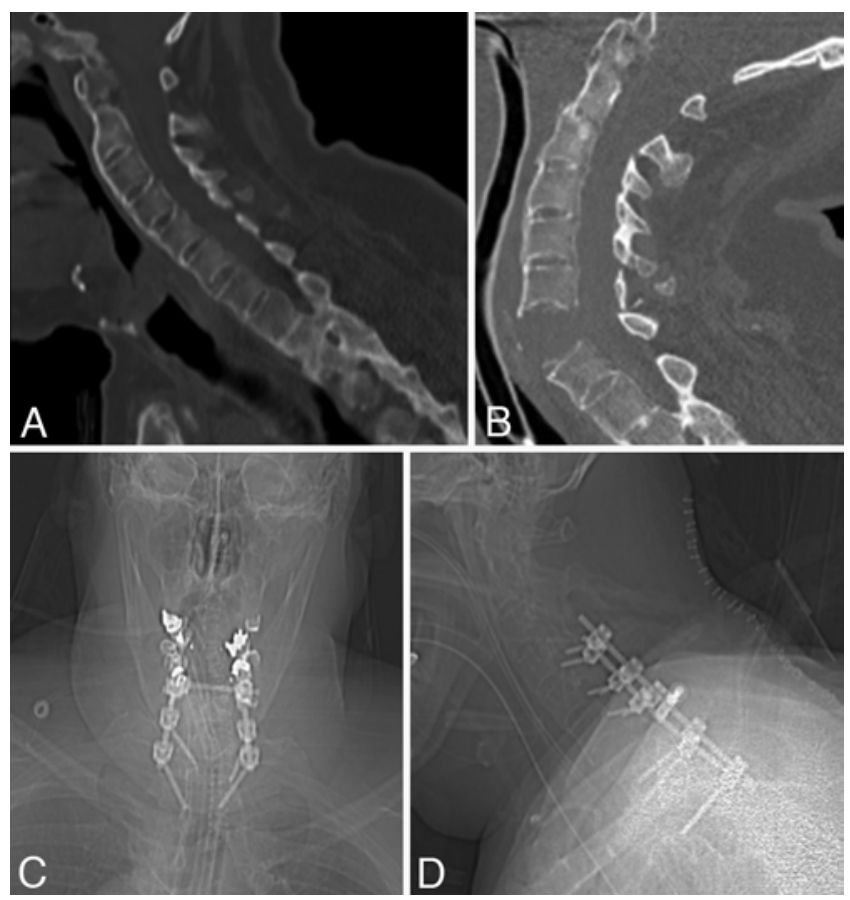

FIG. 1. Case 1. A 68-year-old man with ankylosing spondylitis. Initial CT (A) showed no cervical fracture or acute findings. After emergent intubation, CT (B) showed a fracture-dislocation at C6-7. Postoperative anteroposterior (C) and lateral (D) radiographs after open reduction and C4-T2 posterior fixation.

and near-full strength in his proximal upper extremities and bilateral lower extremities. Imaging revealed diffuse idiopathic skeletal hyperostosis with an acute C6-7 fracture associated with significant spinal cord compression. The patient was urgently taken to the operating room for posterior decompression and C6-T1 fixation (Fig. 2A-C). A unilateral screw was placed at C-7 because the contralateral facet complex was found to be disrupted at the time of surgery.

The patient awoke from surgery neurologically stable but remained in the hospital for treatment of multiple medical problems, including Klebsiella pneumonia and bacteremia. Postoperative radiographs demonstrated good spinal alignment. On postoperative Day 12, the patient developed respiratory distress, presumably due to the pneumonia, and was transferred to the intensive care unit. He required intubation by the pulmonary critical care intensivist. The intubation was prolonged and difficult, but ultimately the airway was secured via direct laryngoscopy. Immediately after intubation, the patient's neurological status deteriorated to C-6 quadriplegia. Imaging revealed spondyloptosis at C6-7 (Fig. 2D).

\section{Operation}

The patient was emergently returned to the operating room for decompression and open reduction, with revision and extension of the posterior fusion from C-3 to T-2 (Fig. $2 \mathrm{E}$ and $\mathrm{F}$ ).

\section{Postoperative Course}

The patient remained quadriplegic and ventilator dependent. In accordance with family wishes, care was 

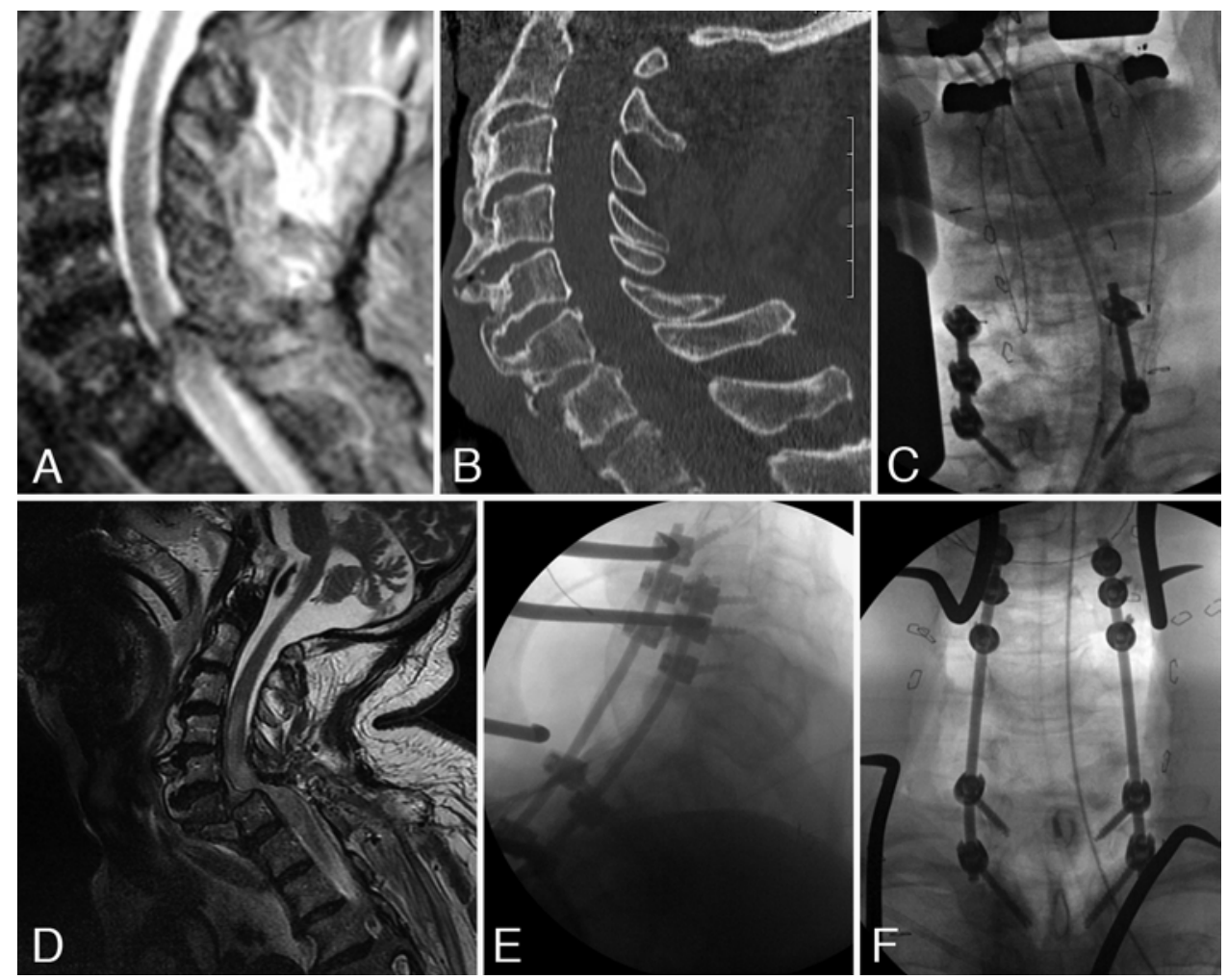

FIG. 2. Case 2. A 73-year-old man with a C6-7 fracture and spinal cord compression (A and B) underwent C6-T1 posterior decompression and fixation (C) at presentation. Postintubation MRI (D) showed new complete spondyloptosis of C6-7. Intraoperative radiographs ( $\mathrm{E}$ and $\mathrm{F}$ ) of subsequent open reduction with revision and extension of posterior fusion from C-3 to T-2.

withdrawn and the patient died 5 days after the second operation.

\section{Discussion}

Patients with cervical instability, deformity, or critical spinal canal stenosis are identified by anesthesiologists, critical care physicians, and neurosurgeons as patients with difficult airways associated with the potential for spinal cord injury related to neck manipulation.,12 These 2 cases illustrate devastating neurological deterioration directly attributable to emergent endotracheal intubation in the intensive care unit. Both patients were male and near the age of 70 years. Each patient had been successfully intubated in the operating room under controlled situations, but both sustained a cervical injury during intubation under emergent conditions. In both cases the emergent airway manipulation resulted in a C6-7 fracture with quadriplegia. Both patients ultimately died of their acquired neurological deficits. Despite these similarities, we identify different risk factors for a complicated intubation in each patient.

Our first patient had ankylosing spondylitis but no cervical spine fracture at admission. Ankylosing spondylitis is a progressive, seronegative, inflammatory rheumatic arthropathy affecting the bony insertion points of ligaments. ${ }^{1}$ The spine and sacroiliac joints are predominantly affected. Over time, the vertebral column ossifies and results in a progressive loss of spinal mobility and a characteristic "bamboo spine" on imaging, which depicts the bridging bone. ${ }^{2}$ Deformity and stiffness lead to decreased functionality and progressive osteoporosis. ${ }^{1,2,11}$ The spine is thus rendered more susceptible to fracture from smaller physical loads, ${ }^{4,23}$ making standard intubation techniques difficult and sometimes impossible.

Although multiple reports have outlined treatment strategies for cervical fractures in patients with ankylosing spondylitis, $4,6,11,23$ the incidence of new cervical fractures and spinal cord injuries that are specifically related to intubation in these patients appears to be exceedingly low. $6,10,19$ Salathé and Jöhr reported the first such case in 1989, but pre- or postintubation radiographs were unavailable, leaving the etiology of the fracture unclear. ${ }^{19} \mathrm{~A}$ second report documented 3 patients with ankylosing spondylitis who became acutely quadriparetic after emergent intubation. ${ }^{6}$ One patient was known to have a C6-7 fracture before the intubation, but details of the other cases were not identified.

We provide a comprehensive report of cervical fracture and spinal cord injury resulting from emergent intubation in a patient with ankylosing spondylitis, the first to remark on pre- and postintubation imaging as documentation of the cervical pathology. Our patient demonstrated no cervical fracture on CT scanning prior to his respiratory decline. Multiple attempts with direct laryngoscopy failed, and intubation was established only after fiberoptic laryngotracheoscopy. We postulate that excessive cervical extension from attempted direct laryngoscopy in the setting of an ankylosing spondylitic spine resulted in the cervical fracture-dislocation. 
Our second patient illustrates a different pathophysiology. Imaging revealed diffuse idiopathic skeletal hyperostosis, but the patient underwent posterior fixation and fusion for a traumatic C6-7 fracture prior to his catastrophic neurological decline. As in our first case, a prolonged and difficult intubation probably resulted in excessive stress on an already compromised cervical spine. However, screw pullout, hardware failure, and subsequent spondyloptosis with spinal cord injury occurred in this second case.

Techniques that might have rendered this patient's initial fusion construct less susceptible to hardware failure include the addition of more rostral and caudal motion segments into the construct or an anterior approach for circumferential fixation. Given the excellent alignment of the patient's spine and good bone quality noted at the first operation, however, these techniques were not used.

To our knowledge, this is the first report of intubation as a cause of significant neurological decline related to the disruption of a recently fixated cervical fracture. The rarity of this event is illustrated by the remarkably small number of cases ascribing cervical spinal cord injury to intubation in patients with spinal instability who have not undergone fixation. No more than 10 such cases have been documented, $, 5,13,15,17$ and these cases probably involved patients with missed cervical fractures. In 1993, Hastings and Kelley described the first case of intubation causing neurological deterioration in a patient with a cervical spine fracture. ${ }^{9}$ This patient probably presented with a C6-7 fracture that was missed on initial triage. Muckart et al. later described 2 cases of new-onset quadriplegia after intubation in polytrauma victims..$^{15}$ In 1 case, cervical spine imaging was not obtained before intubation, but a C-2 fracture was later identified. In the other documented case, initial cervical radiographs were inadequate to visualize a C-6 burst fracture.

The rarity of intubation-related cervical spinal cord injury is also illustrated by a recent 2-institution review of more than 5000 cases over a 37-year period in a closed claims general anesthesia database..$^{10}$ Fewer than $1 \%(\mathrm{n}=$ 37) of these perioperative claims involved cervical spinal cord injuries, the majority of which were attributable to intraoperative factors, such as surgical complications or head and neck positioning for the procedure. Only 4 cases of cervical spinal cord injury were attributable to airway management in this nonemergent, perioperative setting. This report is intriguing not only because of its large scale, but also because it raises the possibility that such events may be underreported because of potential or actual medical malpractice liability.

Several strategies exist for obtaining airway control in patients with cervical spine pathology. ${ }^{3}$ All airway interventions cause spinal movement, ${ }^{18,20}$ but efforts are made to minimize neck manipulation during airway management. Direct laryngoscopy has been proven safe in trauma patients, ${ }^{16}$ and coupling this maneuver with manual in-line stabilization decreases cervical movement. ${ }^{8,22}$ Fiberoptic intubation further decreases neck manipulation, ${ }^{12,18}$ but this technique is more technically challenging. The intubating laryngeal mask airway, ${ }^{21,24}$ nasopharyngeal airway, ${ }^{3,7}$ and emergency cricothyrotomy ${ }^{14}$ are additional options for the patient with a difficult airway.
In our 2 cases, the emergency intubations were performed by individuals subspecialized in trauma anesthesiology or pulmonary critical care medicine. The first case was converted to fiberoptic intubation after direct laryngoscopy had failed. In the second case, direct laryngoscopy was successful only after prolonged effort. No outcome data are available to support a particular practice option for airway management in patients with cervical spine disease, ${ }^{3}$ but these 2 cases encouraged multidisciplinary discussions at our institution regarding optimal airway management in similar patients. Subsequent changes made in the intensive care unit include more readily available cricothyrotomy trays, as well as the placement of visible signs in patient rooms indicating a difficult airway. Ultimately, the most appropriate method for intubation is still decided on an individual basis by the treating physician. Large prospective studies would be required to elucidate any single method of airway control as the safest and most effective in the setting of cervical spine pathology. $3,10,22$

\section{Conclusions}

This report details 2 cases of quadriplegia resulting from emergent intubation of patients with preexisting cervical spine pathology. Case 1 is the first report with radiographic documentation of a cervical fracture-dislocation resulting from intubation in a patient with ankylosing spondylitis. Case 2 is the first report of intubation as a cause of significant neurological decline related to disruption of a recently fixated cervical fracture. Awareness of the potential dangers of airway management in patients with cervical spine pathology is critical for all involved subspecialty team members.

\section{References}

1. Ball J: Enthesopathy of rheumatoid and ankylosing spondylitis. Ann Rheum Dis 30:213-223, 1971

2. Carette S, Graham D, Little H, Rubenstein J, Rosen P: The natural disease course of ankylosing spondylitis. Arthritis Rheum 26:186-190, 1983

3. Crosby ET: Airway management in adults after cervical spine trauma. Anesthesiology 104:1293-1318, 2006

4. Einsiedel T, Schmelz A, Arand M, Wilke HJ, Gebhard F, Hartwig E, et al: Injuries of the cervical spine in patients with ankylosing spondylitis: experience at two trauma centers. J Neurosurg Spine 5:33-45, 2006

5. Farmer J, Vaccaro A, Albert TJ, Malone S, Balderston RA, Cotler JM: Neurologic deterioration after cervical spinal cord injury. J Spinal Disord 11:192-196, 1998

6. Fox MW, Onofrio BM, Kilgore JE: Neurological complications of ankylosing spondylitis. J Neurosurg 78:871-878, 1993

7. Fuchs G, Schwarz G, Baumgartner A, Kaltenböck F, VoitAugustin H, Planinz W: Fiberoptic intubation in 327 neurosurgical patients with lesions of the cervical spine. J Neurosurg Anesthesiol 11:11-16, 1999

8. Gerling MC, Davis DP, Hamilton RS, Morris GF, Vilke GM, Garfin SR, et al: Effects of cervical spine immobilization technique and laryngoscope blade selection on an unstable cervical spine in a cadaver model of intubation. Ann Emerg Med 36:293-300, 2000

9. Hastings RH, Kelley SD: Neurologic deterioration associated with airway management in a cervical spine-injured patient. Anesthesiology 78:580-583, 1993

10. Hindman BJ, Palecek JP, Posner KL, Traynelis VC, Lee LA, 
Sawin PD, et al: Cervical spinal cord, root, and bony spine injuries: a closed claims analysis. Anesthesiology 114:782795, 2011

11. Kanter AS, Wang MY, Mummaneni PV: A treatment algorithm for the management of cervical spine fractures and deformity in patients with ankylosing spondylitis. Neurosurg Focus 24(1):E11, 2008

12. Langford RA, Leslie K: Awake fibreoptic intubation in neurosurgery. J Clin Neurosci 16:366-372, 2009

13. Liang BA, Cheng MA, Tempelhoff R: Efforts at intubation: cervical injury in an emergency circumstance? J Clin Anesth 11:349-352, 1999

14. McGill J, Clinton JE, Ruiz E: Cricothyrotomy in the emergency department. Ann Emerg Med 11:361-364, 1982

15. Muckart DJ, Bhagwanjee S, van der Merwe R: Spinal cord injury as a result of endotracheal intubation in patients with undiagnosed cervical spine fractures. Anesthesiology 87:418-420, 1997

16. Patterson H: Emergency department intubation of trauma patients with undiagnosed cervical spine injury. Emerg Med J 21:302-305, 2004

17. Powell RM, Heath KJ: Quadraplegia in a patient with an undiagnosed odontoid peg fracture. The importance of cervical spine immobilisation in patients with head injuries. J R Army Med Corps 142:79-81, 1996

18. Sahin A, Salman MA, Erden IA, Aypar U: Upper cervical vertebrae movement during intubating laryngeal mask, fibreoptic and direct laryngoscopy: a video-fluoroscopic study. Eur J Anaesthesiol 21:819-823, 2004

19. Salathé M, Jöhr M: Unsuspected cervical fractures: a common problem in ankylosing spondylitis. Anesthesiology 70:869-870, 1989

20. Sawin PD, Todd MM, Traynelis VC, Farrell SB, Nader A, Sato Y, et al: Cervical spine motion with direct laryngoscopy and orotracheal intubation. An in vivo cinefluoroscopic study of subjects without cervical abnormality. Anesthesiology 85:26-36, 1996

21. Sener EB, Sarihasan B, Ustun E, Kocamanoglu S, Kelsaka E, Tur A: Awake tracheal intubation through the intubating laryngeal mask airway in a patient with halo traction. Can J Anaesth 49:610-613, 2002

22. Shatney CH, Brunner RD, Nguyen TQ: The safety of orotracheal intubation in patients with unstable cervical spine fracture or high spinal cord injury. Am J Surg 170:676-680, 1995

23. Thumbikat P, Hariharan RP, Ravichandran G, McClelland MR, Mathew KM: Spinal cord injury in patients with ankylosing spondylitis: a 10-year review. Spine (Phila Pa 1976) 32:2989-2995, 2007

24. Wong JK, Tongier WK, Armbruster SC, White PF: Use of the intubating laryngeal mask airway to facilitate awake orotracheal intubation in patients with cervical spine disorders. J Clin Anesth 11:346-348, 1999

\section{Author Contributions}

Conception and design: Theodore, Oppenlander. Acquisition of data: Oppenlander, Hsu. Analysis and interpretation of data: Oppenlander. Drafting the article: Oppenlander. Critically revising the article: Theodore, Oppenlander, Bolton. Reviewed submitted version of manuscript: Theodore, Oppenlander. Statistical analysis: Oppenlander. Administrative/technical/material support: Oppenlander. Study supervision: Theodore.

\section{Correspondence}

Nicholas Theodore, c/o Neuroscience Publications, Barrow Neurological Institute, St. Joseph's Hospital and Medical Center, 350 W. Thomas Rd., Phoenix, AZ 85013. email: neuropub@dignity health.org. 